\title{
Shoulder Periarthritis and its Imaging Features in Patients with Type 1 Diabetes Mellitus
}

\author{
Abhilash Nair', Devasenathipathy Kandasamy ${ }^{2}$, Raju Sharma', HL Nag ${ }^{3}$, \\ Upiderpal Singh ${ }^{4}$,Himani Bhatia ${ }^{5}$,Soma Saha ${ }^{5}$, Nikhil Tandon $^{5}$, R. Goswami ${ }^{5}$ \\ Dept. of Endocrinology and Metabolism, Government Medical College, Thiruvananthapuram ${ }^{1}$, \\ Dept. of Radio-diagnosis ${ }^{2}$, Dept. of Orthopedics, \\ Dept. of Physical Medicine and Rehabilitation ${ }^{4}$, Dept. of Endocrinology and Metabolism ${ }^{5}$, \\ All India Institute of Medical Sciences, New Delhi.
}

\begin{abstract}
Aim: There is limited information on periarthritis/adhesive capsulitis of the shoulder (ACS) in patients with type-1-diabetes mellitus (T1D). We assessed the prevalence and characteristics of ACS in patients with type-1-diabetes mellitus.

Methods: Consecutive 267 patients attending 'Diabetes of Young Clinic' were screened for ACS. Those with clinical features of ACS were further assessed by 'shoulder pain and disability index' (SPADI), radiograph and MRI of the shoulder. The average glycemic status (HbA1c) during preceding 2 years was assessed in patients with and without ACS. Controls were age and sex matched healthy subjects (1:1 ratio).

Results: Sixteen of 267 patients (6.0\%) with type-1-diabetes had clinical features of ACS, unlike none of the healthy controls $(\mathrm{P}<0.001)$. Internal and external rotation of the shoulders was the most frequently restricted movements in ACS. Thickened coracohumeral ligament and axillary pouch obliteration was characteristic MRI feature, present in $80.0 \%$ in $73.3 \%$ cases, respectively. Though 14/16 type-1-diabetes patients with ACS were symptomatic, they never reported these complaints in diabetic clinic with the treating physicians. On regression analysis (odds ratio; $95 \% \mathrm{CI}$ ), duration of diabetes $(1.1 ; 1.03-1.17, \mathrm{P}<0.01)$, retinopathy $(3.6 ; 1.05-12.52, \mathrm{P}=0.04)$, and limited joint mobility $(6.4 ; 1.88-21.95, \mathrm{P}<0.01)$ were independent predictors for presence of ACS in type-1-diabetes. The mean $\mathrm{HbA} 1 \mathrm{c}$ and lipid levels were comparable in patients with or without ACS.
\end{abstract}

Conclusions: Six percent of patients with type-1-diabetes had ACS, which can be detected on clinical screening and confirmed by imaging to help initiate early treatment.

Keywords: Type1 Diabetes, complications.

\section{Introduction}

Adhesive capsulitis of the shoulder (ACS) is a painful and functionally limiting condition (1). It is characterized by pain, stiffness and progressive restriction inactive and passive range of motion of the glenohumeral joint. It is observed in up to $20-25 \%$ of patients with type 2 diabetes and shows variable association with the severity of hyperglycemia and hyperlipidemia (2-5). Patients with type 1 diabetes might also show similar association with ACS (6).

Correspondence : Dr. Ravinder Goswami, MD, DM (Endocrinology), Department of Endocrinology and Metabolism, All India Institute of Medical Sciences, New Delhi-110029. Email: gosravinder@hotmail.com. 
However, to date there is no systematic study describing the clinical aspects, prevalence and imaging features of ACS in patients with Type 1diabetes. Here we describe the prevalence of ACS, clinical features, related disability and the magnetic resonance imaging (MRI) characteristics of ACS in a large cohort of 267 patients with type 1 diabetes.

\section{Material and Methods}

Patients with type-1-diabetes were recruited from the 'Diabetes of Young Clinic' at 'All India Institute of Medical Sciences', New Delhi. Patients with onset of diabetes $<30$ years of age are registered and followed-up in this clinic since 1990. All the patients attending the clinic during a six-month period were examined for the presence of adhesive capsulitis of shoulder by a clinician and an occupational therapist (authors AN and HB). Those with duration of diabetes less than two years, pregnancy, history of trauma or any other disease affecting the shoulder region were excluded. The details of duration, onset of diabetes, associated thyroid dysfunction, presence of retinopathy (as confirmed by ophthalmologist) and GAD65 autoantibody positivity were noted from the records of the patients maintained in the clinic. Peripheral neuropathy was assessed using symptoms and signs scores as suggested by Meijer et al (7). Estimated glomerular filtration rate (eGFR) was calculated as suggested by Cockcroft and Gault (8). Glycemic control was assessed by average of the last four $\mathrm{HbAlc}$ values of the patients. A fresh blood sample was also drawn for their current $\mathrm{HbA} 1 \mathrm{c}$.

\section{Diagnosis of Adhesive Capsulitis}

ACS was diagnosed based on the criteria suggested by the 'American shoulder and elbow association' (9-11). The essential criteria were restriction of active and passive movements of the shoulder and absence of other intrinsic shoulder disorders. Restriction of shoulder movements was assessed by Apley's scratch physical test (9). In this test, patients were asked to reach behind the head and touch the superior aspect of the opposite scapula with the hand to assess their abduction and external rotation. Internal rotation and adduction of the shoulder were tested by asking the patient to reach behind the back and touch the inferior aspect of the opposite scapula. Patients with positive Apley's test were examined by an orthopedic expert (authors HLN). The range of shoulder joint motion in active condition was quantified during flexion, extension, abduction external and internal rotation using a universal goniometer (Baseline, New York). A restriction of movement of more than $25 \%$ in any of these was considered significant. To assess association between ACS and limited joint mobility (LJM) of hand, patients were also examined for the presence of 'prayer sign' (12).

\section{Shoulder Pain and Disability Index (SPADI)}

Pain and functional loss related to ACS were assessed by SPADI as per the recommendation of 'American Physical Therapy Association' (13-15). SPADI is a selfadministered questionnaire with five questions on severity of pain and eight questions on disability during activities of daily living. Responses to the questions were graded on visual analog scale where ' 0 ' indicated no pain/disability and 10 being the maximum. The highest possible scores for pain and disability were 50 and 80 , respectively.

\section{Imaging for the Shoulder Joint}

Patients with restricted movements were subjected to radiography and non-contrast MRI of the affected shoulder joint. If restriction was present in both the shoulder joints, the more severely affected one was imaged. The MR scans were evaluated by two radiologists (authors, RS and DK) and findings were recorded by consensus.

Controls were healthy nursing and medical students of the Institute and acquaintances of the patients. They were age and 
sex matched ( \pm two years) in 1:1 ratio with the patients' cohort. The study was approved by the ethics committee of the All India Institute of Medical Sciences, New Delhi. Written informed consent was obtained from all the subjects undergoing radiographs and MRI studies. The work was carried out with the support of financial grant from Indian council of Medical Research (\#5/4/5-5/Diab.-16-NCD-II).

\section{Statistical Analysis}

Data are shown as mean $\pm \mathrm{SD}$ with frequencies in percentage. The clinical and biochemical characteristics of patients with and without ACS were compared by parametric and nonparametric tests as appropriate. The differences in the frequency of ACS between patients and controls were compared using Fisher's exact test. A two tailed $\mathrm{P}$ value $<0.05$ was considered significant.

\section{Results}

Figure 1 shows the flow of patients in the study. A total of 300 subjects with type-1diabetes attended the clinic during the study period. Controls included 267 subjects during the same period. Two hundred ninety of type-1diabetes could be contacted to participate in the study. Twenty three of 290 subjects with type-1diabetes were excluded for various reasons (significant injury around shoulder in the past, $\mathrm{n}$ $=9$; duration of diabetes $<2$ yrs, $n=9$; and $n=$ one patient each with severe kyphoscoliosis, multiple sclerosis, furuncle over shoulder, past history of joint tuberculosis and age of onset of diabetes $>30 \mathrm{yrs})$. Final results are reported for a total of 267 patients (M:F 134:133). Table 1 shows the clinical characteristics and biochemical features of the patients. Their mean age, body mass index and duration of diabetes were $26.6 \pm 10.7$ years, $20.4 \pm 3.7 \mathrm{~kg} / \mathrm{m} 2$ and $13.0 \pm 8.4$ years respectively. Thyroid dysfunctions were present in $38(14.2 \%)$ of them (hypothyroidism, $\mathrm{n}=35$, and Graves' disease, $\mathrm{n}$ $=3$ ). However, all these patients were euthyroid on appropriate treatment. History of diabetic ketoacidosis was present in 189 patients. GAD65 antibody was positive in 103 of the 181 type-1-diabetes patients in whom test results were available. Limited joint mobility of hand joints was present in $30(11.2 \%)$ of type-1diabetes patients.

The M:F ratio and the mean age of the healthy controls (134:133 and $26.9 \pm 10.8$ years) was comparable to that of type-1-diabetes patients $(\mathrm{P}=0.96$ and 0.72 , respectively $)$.

\section{Prevalence of Adhesive Capsulitis}

Sixteen of the 267 patients with type-1diabetes $(6.0 \%)$ had clinical features of ACS. In contrast, none of the controls showed restriction of any movement of the shoulder joints $(\mathrm{P}<$ $0.001)$. Restriction of internal $(\mathrm{n}=13)$ and external rotation $(n=8)$ were the most common abnormalities and all of them demonstrated restriction of either one or both of these movements. In addition, extension was restricted in seven of them and flexion and abduction movements were restricted in three each. The range of shoulder joint movements on goniometry was reduced by $40 \pm 11.4 \%$ for internal rotation, $31 \pm 17.8 \%$ for external rotation, $19 \pm 19.4 \%$ for abduction, $23 \pm 11.6 \%$ for extension and $17.2 \pm 16.2 \%$ for flexion. The median SPADI scores for pain and disability were 6 (range 0-29) and 14 (range 0-49), respectively.

\section{Clinical Characteristics of Patients with and without Adhesive Capsulitis of Shoulder}

Table 1 shows the clinical and biochemical characteristics of patients with and without ACS. The mean age $(37.0 \pm 11.6$ years $)$ and duration of diabetes (24.1 \pm 11.6 years) of patients with ACS were significantly different from those with no $\operatorname{ACS}(26.3 \pm 10.36$ years and $12.5 \pm 7.62$ years, $P$ $<0.01$ and $\mathrm{P}<0.05$, respectively). The prevalence of retinopathy and neuropathy was significantly higher in patients with adhesive capsulitis compared to those with no such features (Table 1). Similarly, LJM was present in 


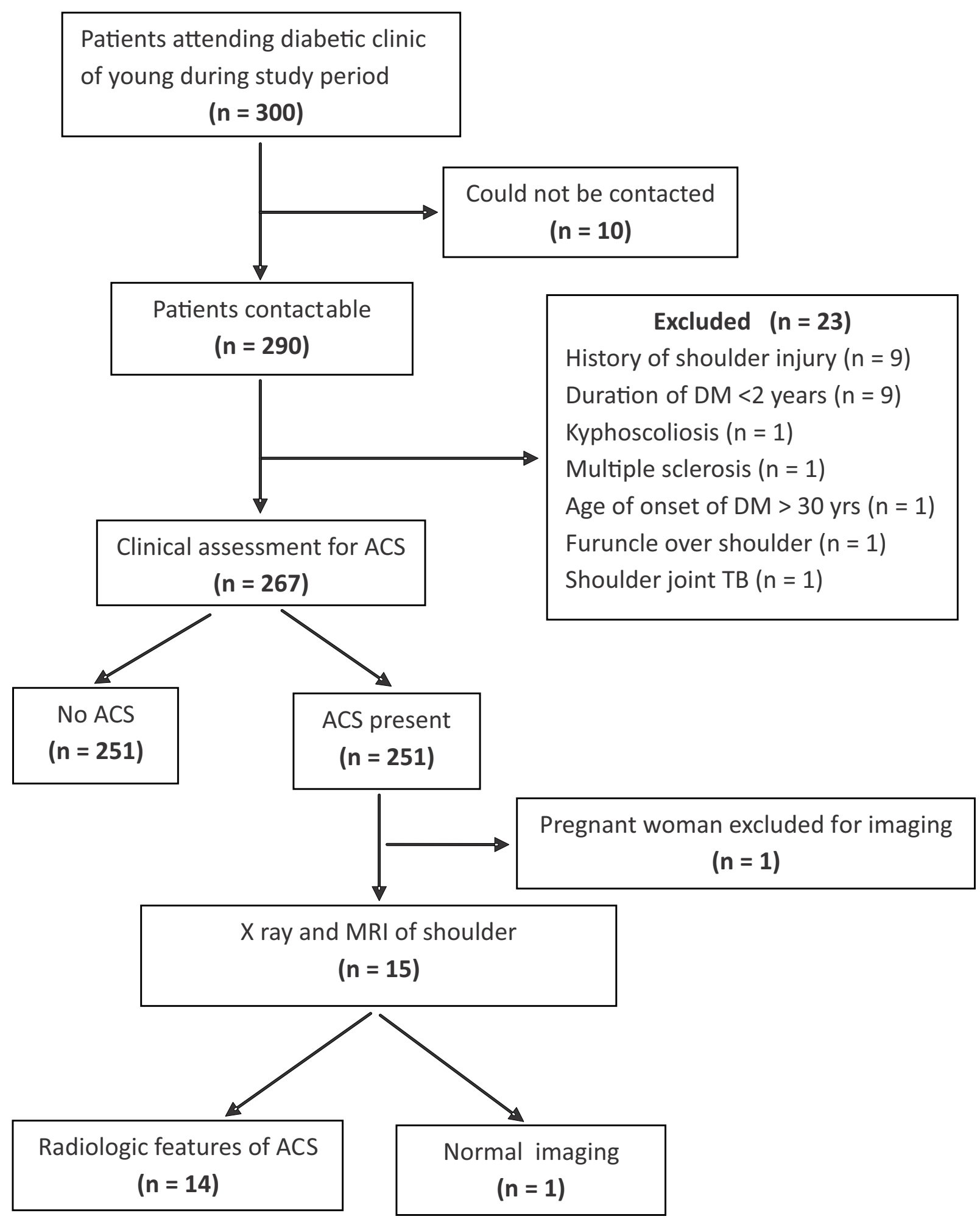

Fig. 1: Flow of patients in the study 
Table 1: Characteristics of type 1 diabetes patients with and without adhesive capsulitis of shoulder

\begin{tabular}{|c|c|c|c|}
\hline \multirow[b]{2}{*}{ Parameters } & \multicolumn{2}{|c|}{ Adhesive capsulitis } & \multirow[b]{2}{*}{ Pvalue } \\
\hline & $\begin{array}{l}\text { Present } \\
(n=16)\end{array}$ & $\begin{array}{r}\text { Absent } \\
(n=251)\end{array}$ & \\
\hline Sex (M:F) & $7: 9$ & $127: 124$ & 0.59 \\
\hline Age ( years $)$ & $37.0 \pm 11.6$ & $26.0 \pm 10.4$ & $<0.001$ \\
\hline Duration of diabetes (years) & $24.1 \pm 11.6$ & $12.3 \pm 7.6$ & $<0.001$ \\
\hline Body mass index $\left(\mathrm{Kg} / \mathrm{m}^{2}\right)$ & $21.2 \pm 3.8$ & $20.3 \pm 3.8$ & 0.37 \\
\hline Hypothyroidism (\%) & $12.5 \%$ & $13.1 \%$ & 0.97 \\
\hline Current HbA1c (\%) & $9.0 \pm 2.5$ & $9.2 \pm 2.2$ & 0.82 \\
\hline Average pooled $\mathrm{HbA1c}(\%)$ & $9.0 \pm 2.0$ & $9.2 \pm 2.7$ & 0.73 \\
\hline Total cholesterol (mg/dL) & $169 \pm 28.8$ & $165 \pm 34.3$ & 0.70 \\
\hline Serum triglycerides (mg/dL) & $107 \pm 48$ & $100.4 \pm 52.0$ & 0.61 \\
\hline Serum LDL(mg/dL) & $90 \pm 30$ & $92.5 \pm 28.3$ & 0.73 \\
\hline Serum HDL(mg/dL) & $54.5 \pm 13.5$ & $54.0 \pm 17.6$ & 0.88 \\
\hline Proteinuria $>150 \mathrm{mg} /$ day $(\mathrm{n})$ & $1(6.2 \%)$ & $20(8.3 \%)$ & 0.77 \\
\hline Serum creatinine $(\mathrm{mg} / \mathrm{dL})$ & $0.8 \pm 0.3$ & $0.8 \pm 1.1$ & 0.99 \\
\hline eGFR $<60 \mathrm{ml} /$ minute & $2(12.5 \%)$ & $18(7.1 \%)$ & 0.34 \\
\hline Diabetic retinopathy (n) & $9(56.2 \%)$ & $32(12.7 \%)$ & $<0.05$ \\
\hline Neuropathy (n) & $9(56.2 \%)$ & $31(12.4 \%)$ & $<0.05$ \\
\hline Limited joint mobility ( \% ) & $43.7 \%$ & $9.6 \%$ & $<0.001$ \\
\hline
\end{tabular}

higher proportion in patients with ACS as compared to those with no ACS (43.7\% vs. $9.6 \%, \mathrm{P}<0.05$ ). On regression analysis (odds ratio and $95 \% \mathrm{CI}$ ) with $\mathrm{ACS}$ as dependent variable, only duration of diabetes (1.1 and 1.03$1.17, \mathrm{P}<0.01)$, presence of retinopathy (3.6 and $1.05-12.52, \mathrm{P}=0.04)$, and limited joint mobility (6.4 and 1.88-21.95, $\mathrm{P}<0.01)$ were independent predictors for presence of ACS in type-1diabetes.

The M:F ratio, mean BMI, frequency of thyroid dysfunction, proteinuria (>150 mg/day), mean serum creatinine and lipids were comparable in patients with and without ACS (Table 1). The mean current HbA1c $(9.0 \pm 2.5 \%$ vs. $9.2 \pm 2.15 \%)$ and pool of last four HbA1c values $(9.0 \pm 2.0 \%$ and $9.2 \pm 2.70 \%)$ were comparable between the two groups $(\mathrm{P}=0.82$ and 0.73 , respectively).

\section{MRI Features}

Fifteen of the 16 patients with ACS underwent radiography and MRI of the shoulder. One patient was pregnant and was excluded from imaging. Table 2 shows the frequencies of salient features of ACS on MRI. Thickening of the coraco-humeral ligament was the most frequent abnormality $(\mathrm{n}=12,80 \%)$, followed by axillary pouch obliteration $(\mathrm{n}=11,73.3 \%)$ (Fig. 2). Other features included thickening of capsule over axillary pouch $(\mathrm{n}=8,53.3 \%)$, sub-coracoid fat pad obliteration $(n=8,53.3 \%)$ and supraspinatus tendinitis $(\mathrm{n}=4,26.6 \%)$. On plain radiograph, four of $15(26.6 \%)$ also had sclerosis of the greater tuberosity of humerus.

\section{Discussion}

In the present study, patients with type 1 
Table 2: Frequency of abnormalities detected on MRI in 15 diabetes patients with adhesive capsulitis of the shoulder

\begin{tabular}{|c|c|c|c|c|c|c|}
\hline & $\begin{array}{c}\text { Coracohumeral } \\
\text { ligament } \\
\text { thickening }\end{array}$ & $\begin{array}{c}\text { Axillary } \\
\text { pouch } \\
\text { obliteration }\end{array}$ & $\begin{array}{c}\text { Thickening } \\
\text { of capsule } \\
\text { over } \\
\text { axillary } \\
\text { pouch }\end{array}$ & $\begin{array}{c}\text { Subcoracoid } \\
\text { fat pad } \\
\text { obliteration }\end{array}$ & $\begin{array}{c}\text { Supraspinatus } \\
\text { tendinitis }\end{array}$ & $\begin{array}{l}\text { Frequency } \\
\text { of } \\
\text { combination }\end{array}$ \\
\hline $\begin{array}{c}\text { Combination } \\
1\end{array}$ & + & + & + & + & + & 1 \\
\hline $\begin{array}{c}\text { Combination } \\
2\end{array}$ & + & + & + & + & - & 5 \\
\hline $\begin{array}{c}\text { Combination } \\
3\end{array}$ & + & + & + & - & + & 1 \\
\hline $\begin{array}{c}\text { Combination } \\
4\end{array}$ & - & + & + & - & + & 2 \\
\hline $\begin{array}{c}\text { Combination } \\
5\end{array}$ & + & + & - & - & - & 2 \\
\hline $\begin{array}{c}\text { Combination } \\
6\end{array}$ & + & - & - & + & - & 1 \\
\hline $\begin{array}{c}\text { Combination } \\
7\end{array}$ & + & - & - & - & + & 1 \\
\hline $\begin{array}{c}\text { Combination } \\
8\end{array}$ & - & + & - & - & - & 1 \\
\hline $\begin{array}{c}\text { No } \\
\text { abnormality }\end{array}$ & - & - & - & - & - & 2 \\
\hline
\end{tabular}

$+\mathrm{ve}=$ present, $-\mathrm{ve}-=$ absent

diabetes were actively screened for the presence of ACS of shoulder, its significance on their daily activities and the imaging characteristics were assessed. Further, association of ACS with glycemic control and other chronic complications of diabetes were sought. The study revealed a $6.0 \%$ prevalence of ACS among patients with type-1-diabetes. The observed prevalence was similar to that of Arkkila et al., who also observed $10.3 \%$ prevalence of ACS in type-1-diabetes. The mild difference in prevalence rate of ACS in type-1-diabetes observed by Arkkila et al., could be due to the higher age and duration of diabetes of their cohort (higher by five years each). Interestingly, the longer duration of diabetes with ACS was also forthcoming in the present study. In the present study, on an average, patients with ACS were a decade older than those without ACS and also had longer duration of diabetes by 12 years compared to those with no feature of ACS.
The patients with ACS had longer duration of diabetes and prevalence of diabetic complications of neuropathy and retinopathy (56.2\% for each) as compared to those with no ACS. With each year increase in duration of diabetes, the prevalence of ACS increased by $11 \%$. The odds of presence of ACS in type-1diabetes patients were 6.4 times higher if they had LJM. The occurrence of ACS with increasing duration of diabetes and microvascular complications justifies its reference as another form of chronic complication among patients with type-1diabetes. Despite association of ACS with chronic complications, we did not observe a significant difference in the HbAlc levels between patients with and without ACS. There has been no systemic study on the association of long term glycemic control with ACS in patients with type-1-diabetes. However, patients with type 2 diabetes show variable association of glycemic status with ACS (16-19). Prospective 

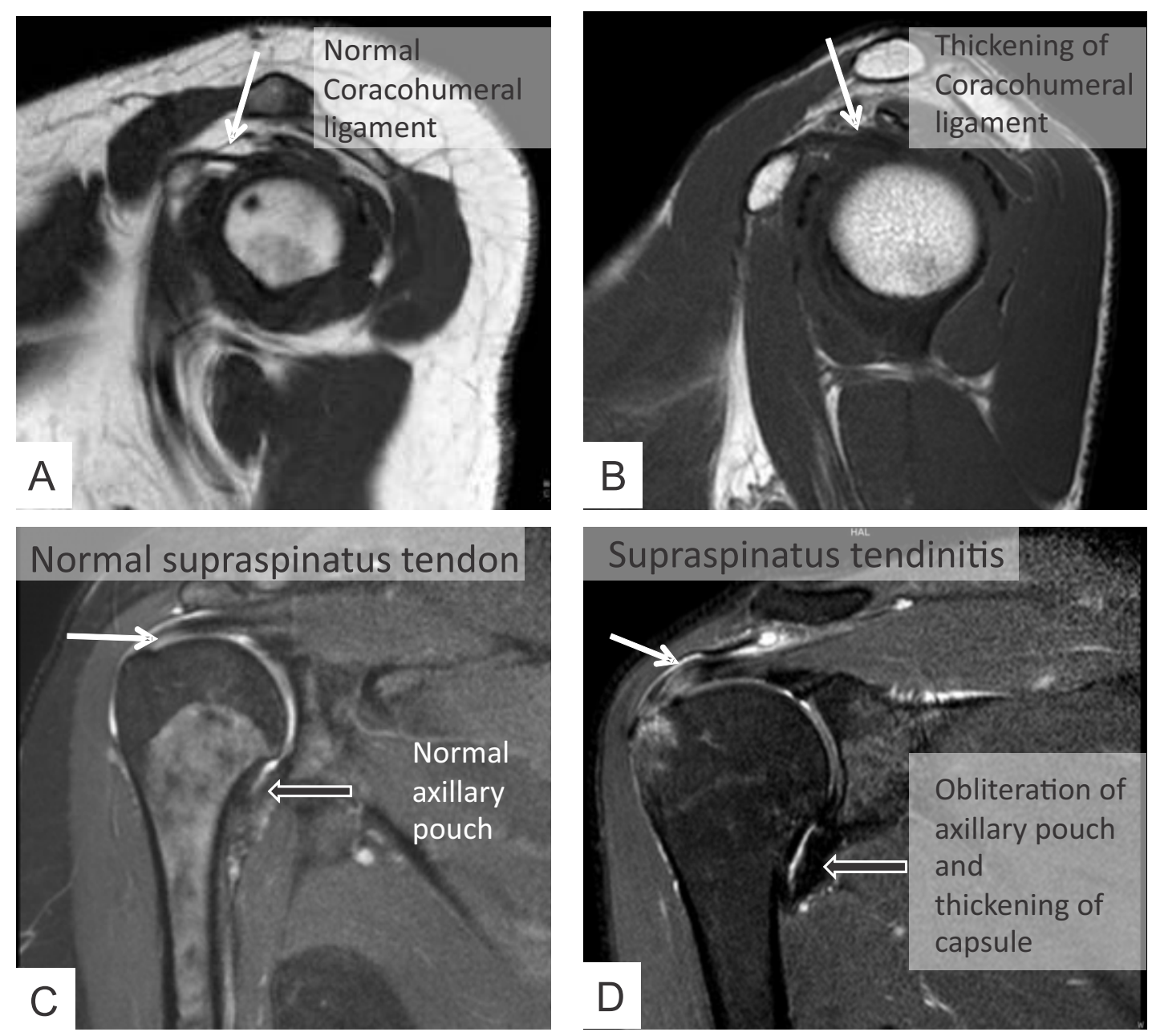

Fig. 2: T1 weighted MR images (A, B) in sagittal oblique plane showing normal appearance of coracohumeral ligament (arrow in image $A$ ) and abnormally thickened coracohumeral ligament with surrounding fat stranding (arrow in image B). T2 weighted fat suppressed images $(C, D)$ in coronal oblique plane showing normal axillary pouch (black arrow in image $C$ ) and thickening of capsule with obliteration of axillary pouch (black arrow in image $D$ ). There is supraspinatus tendinitis with associated marrow edema also seen (white arrow in image D).

studies would help understand the interplay between long term glycemic control and ACS.

The restricted shoulder movements were functionally relevant as revealed by mild to moderate impairment in SPADI score for pain and disability. Shoulder pain and disability could lead to difficulty in concentrating, working and interference in their daily activities like insulin injection and physical exercise involving upper limb. Interestingly, despite evidence of ACS and its functional impact, 14 of the 16 patients with
ACS were newly detected in the study. These patients were referred for expert care. The reasons for inability of the patients to seek medical advice by a majority of the patients are not known. However, several factors could be contributory including lack of awareness of this condition or their pre-occupation with a host of other problems related to diabetes. Notwithstanding these, the current study shows that ACS could be a significant problem in patients with type-1-diabetes akin to type 2 diabetes and needs to be assessed during routine 
follow-up. The present study also showed that coraco-humeral ligament thickening and/or axillary pouch obliteration in more than $90 \%$ of them on MRI could provide objectivity to the clinical diagnosis of ACS.

\section{Conflict of Interest}

There are no conflicts of interest relevant to this article among the authors.

\section{References}

1. Hsu JE, Anakwenze OA, Warrender WJ, Abboud JA (2011). Current review of adhesive capsulitis. J Shoulder Elbow Surg 20: 502-514.

2. Pal B, Anderson J, Dick WC, Griffiths ID (1986). Limitation of joint mobility and shoulder capsulitis in insulin- and noninsulin-dependent diabetes mellitus. $\mathrm{Br} J$ Rheumatol 25: 147-151.

3. Bridgman JF (1972). Periarthritis of the shoulder and diabetes mellitus. Ann Rheum Dis 31: 69-71.

4. Balci N, Balci MK, Tüzüner S (1999). Shoulder adhesive capsulitis and shoulder range of motion in type II diabetes mellitus. J Diabetes Complications 13: 135-140.

5. Ahmad S, Rafi MS, Siddiqui IA, Hamidi K, Faruq NM (2012). The frequency of adhesive capsulitis in diabetes mellitus patients. PakJ Rehabil 1:49-55.

6. Arkkila PE, Kantola IM, Viikari JS, Rönnemaa T (1996). Shoulder capsulitis in type 1 and type 2 diabetic patients: association with diabetic complications and related diseases. Ann Rheum Dis 55: 907-914.

7. Meijer JW, Smit AJ, Sonderen EV, Groothoff JW, Eisma WH, Links TP (2002). Symptom scoring systems to diagnose distal polyneuropathy in diabetes: the Diabetic Neuropathy Symptom score. Diabet Med 19: 962-965.

8. Cockcroft DW, Gault MH (1976). Prediction of creatinine clearance from serum creatinine. Nephron 16: 31-41.
9. Zuckerman JD, Cuomo F (1993). Frozen Shoulder. In: The Shoulder: A Balance of Mobility and Stability. Matsen FA III, Fu FH, Hawkins RJ, eds. Rosemont, ILL: American Academy of Orthopaedic Surgeons, 253-267.

10. Zuckerman J, Cuomo F, Rokito S (1994). Definition and classification of frozen shoulder: a consensus approach. $J$ Shoulder Elbow Surg 3:S72.

11. Woodward TW, Best TM (2000). The painful shoulder: part II. Acute and chronic disorders. American Family Physician 61:3291-3300.

12. Rosenbloom AL (1989). Limitation of finger joint mobility in diabetes mellitus. $J$ Diabetes Complicat 3:77-87.

13. Breckenridge JD, McAuley JH (2011). Shoulder Pain and Disability Index (SPADI). JPhysiother 57:197.

14. Roy JS, MacDermid JC, Woodhouse LJ (2009). Measuring shoulder function: a systematic review of four questionnaires. Arthritis Rheum 61: 623-632.

15. Kelley MJ, Shaffer MA, Kuhn JE, et al (2013). Shoulder pain and mobility deficits: adhesive capsulitis. J Orthop Sports Phys Ther 43: A1-A31.

16. Laslett LL, Burnet SP, Jones JA (2008). Predictors of shoulder pain and shoulder disability after one year in diabetic outpatients. Rheumatology 47:1583-1586.

17. Perlmutter GS, Sabbagg K, Apruzzese W, Cagliero E, Nathan DM (2001). Adhesive Capsulitis of the Shoulder: A Comprehensive Study. Ortho J Harvard Med School 3: 100-102.

18. Zreik NH, Malik RA, Charalambous CP (2016). Frozen shoulder and diabetes: a meta-analysis of prevalence. Muscles Ligaments Tendons J 6: 26-34.

19. Matloub AA, Al-Lehibi KI, Abdul-Gafour WA (2010). Frozen Shoulder in type 2 diabetes mellitus. $\mathrm{Al}$ - Kindy $\mathrm{Col} \mathrm{Med} J$ 6: 95-100. 